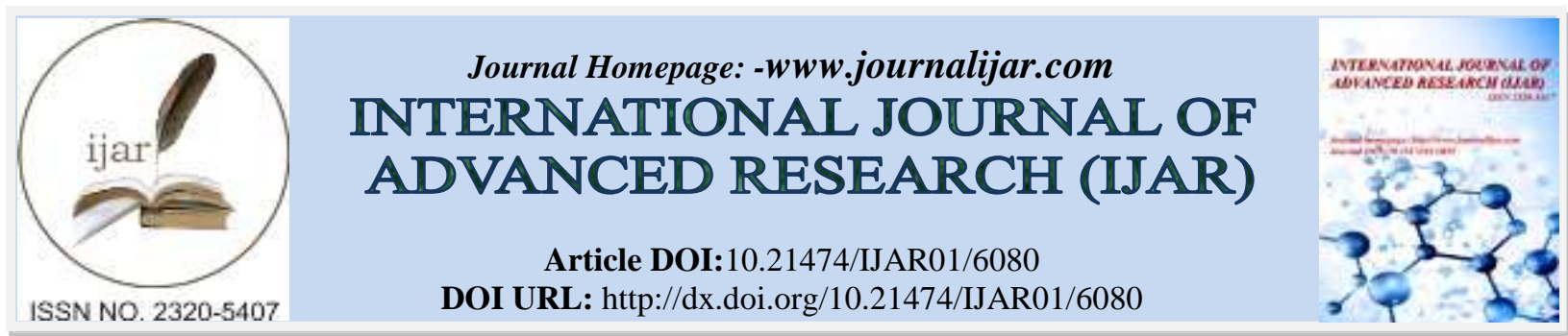

RESEARCH ARTICLE

\title{
KNOWLEDGE, ATTITUDE AND PRACTICE, REGARDING MATERNITY CARE AMONG MARRIED WOMEN RELATED TO AGE, EDUCATION AND ANTENATAL CARE IN DIFFERENT MATERNITY HOMES OF CENTRAL DISTRICT KARACHI, PAKISTAN.
}

\author{
Farhat Jehan $^{1}$, Nazia Jameel ${ }^{2}$ and Rubina Ghani ${ }^{3}$. \\ 1. Department of Community Medicine, Department of Biochemistry. \\ 2. Baqai Medical University, Jinnah Medical \& Dental College. \\ 3. Dadbhoy Institute of Higher Education, Pathological and Molecular Laboratories, Karachi.
}

\section{Manuscript Info}

Manuscript History

Received: 17 October 2017

Final Accepted: 19 November 2017

Published: December 2017

Key words:-

Knowledge, Morbidity, Attitude, Mortality And Maternal Health Care.

\section{Abstract}

Objective:This study aims to assess the knowledge, attitudes and practices regarding on maternal health care and the contributing factors to being knowledgeable among married women age between 15 to 45 years of Central District of Karachi, Pakistan

Material and Methods:Study Design and Setting: The study was observational cross sectional study and this study was carried randomized selected in maternity homes of Liaquatabad Town, North Nazimabad Town, Gulberg Town, New Karachi Town women, Karachi; that are involve in dealing with married Women Age between 15 to 45 years in different maternity homes of central district Karachi.

Study Duration:This proposed study was conducted on human subject, over a period of 6 months.

Sample Size: Totally 385 were interviewed and completed the selfadministered questionnaire after obtaining informed consent.Data would be coded, entered and analyzed using SPSS (version 16.0) package. Data was expressed in percentage.

Result: Total of 385 married women attending maternity health care were interviewed using cluster sampling method.The age distribution was, such that $72.9 \%$ of the respondents were 20 to 34 , age at marriage $74.0 \%$ were above 20 years, $32.7 \%$ of them received High school education, $67.5 \%$ of the participants were house wife and $74.0 \%$ of them were between 1 to 4 previous deliveries. Previous induced/ spontaneous abortion were asked to married pregnant women $70.9 \%$ answered was no. Status of women to their husband's status we found that $74.5 \%$ of them were Karachi residences and $43.1 \%$ received High school education. $58.9 \%$ were of women whose husbands worked in business or services and $34.0 \%$ of women visited antenatal care once time and $30.1 \%$ of women visited antenatal care three times. $>94.2 \%$ women knew that antenatal care is important and agreed with first antenatal examination be done within the first 3 months, anemia is prevented by eating more iron-containing food during pregnancy, $84.9 \%$ of answer was affirmative, need calcium supply, $90.1 \%$ answer 
was positive. Our study results are satisfied with antenatal care, information given to them by doctors about delivery.

Conclusion:The awareness regarding the importance of maternity health care is the need of this era. The antenatal checkups are helpful to mothers as well as to the fetus.

Copy Right, IJAR, 2017,. All rights reserved.

\section{Introduction:-}

Nearly two decades after the Safe Motherhood Initiative was launched, maternal mortality remains the human development indicator showing the widest disparity between rich and poor nations, with the lifetime risk of a woman dying from causes related to pregnancy and childbirth nearly 40 times higher in developing than developed countries. Large rich-poor differences in maternal mortality also exist within developing countries. It is well known that many maternal health problems can be prevented with appropriate antenatal, delivery, and postnatal care. However, despite international and government efforts to increase the provision of a basic package of essential maternal health services, the majority of women in developing countries are still not able to access these potentially life-saving services. In poor countries, shortages of skilled health workers and equipped facilities, and the oftenunequal distribution of existing health resources, create barriers to care for large segments of the population. Women's use of care tends to be further restricted by educational, social, cultural, and financial factors.

Pakistan is a developing country with a population of 130 million. Low literacy and high fertilitycoupled with poor economy translates into increased morbidity and mortality. Health knowledge is one of the important factors make women to be aware of their rights and health status in order to seek suitable health services. There are very few studies addressing on maternal health care in women's of Karachi, Pakistan and the association between socio economic and demographic factors, knowledge and attitude on maternal health care haven't be well concerned in this sub - population. This study aims to assess the knowledge, Attitude and Practices regarding maternal health care and the contributing factors to being knowledgeable among married women age between 15-45 years in different maternity homes of Central District of Karachi, Pakistan.

Karachi is the metropolitan city of Pakistan, but still the healthcare system of the metropolitan city is not up to standard. The central district is amongst the largest district of Karachi. The main aim of the study was:

1. To reduce the maternal morbidity and mortality rate of married woman age between 15 to 45 years,

2. To improving the existing knowledge and practices of woman regarding maternal care in central district of Karachi.

\section{Material AndMethods:-}

The cross sectional study was carried out which was randomized in selecting the maternity homes fron different areas of Karachi, Pakistan. The areas selected for the sample were Liaquatabad, North Nazimabad, Gulberg and New Karachi. The age of the women selected in this study was between 15 to 45 years and married going to different maternity homes in the central district of Karachi.

The sample size was $n=385$. All the women were interviewed and completed the self- administered questionnaire after obtaining informed consent. The samples were selected from public or private maternity homes, dealing with married Women Age between 15 to 45 years in different maternity homes of central district Karachi. Those samples were excluded from interior areas of central Karachi district and also from those who refuse to give consent.

The questionnaire was designed to include information regarding gravidity, parity, number of children. Women were also asked about their previous antenatal care, previous deliveries. Information was gained about the women and their husband's educational and socioeconomic status. They were also enquired about any familial or social constraints regarding regular antenatal care and importance of hospital delivery. They were asked about diet (how many times did they eat meat), iron and calcium supplementation during pregnancy. The data was collected and analyzed by using SPSS (version 16.0) package. Data was expressed in frequencies and percentages.

\section{Results:-}

After collecting the data from the questionnaire, the frequency of the age distribution the respondents was $72.9 \%$ that was between 20 to 34 years, age at marriage $74.0 \%$ were above 20 years, $32.7 \%$ of them received High school 
education, $67.5 \%$ of the participants were house wife and $74.0 \%$ of them were between 1 to 4 previous deliveries. The residence and educational status of women to their husband's status was found to be $74.5 \%$ and $43.1 \%$ received High school education as shown in table 1.

\begin{tabular}{|l|l|}
\hline VARIABLE $(\mathrm{n}=385)$ & FREQUENCY (\%). \\
\hline $\begin{array}{l}\text { Age Groups } \\
\text { (in years) }\end{array}$ & \\
\hline $15-19$ & $64(16.6)$ \\
$20-34$ & $281(72.9)$ \\
$35-45$ & $40(10.3)$ \\
\hline Age at Marriage & \\
\hline$<20$ & $100(25.9)$ \\
\cline { 2 - 2 }$>20$ & $285(74.0)$ \\
\hline Education of Women & $125(32.4)$ \\
\hline Professional college or higher & $126(32.7)$ \\
High school & $48(12.4)$ \\
Primary school & $86(22.3)$ \\
Illiterate & \\
\hline Previous deliveries & $52(13.5)$ \\
\hline 0 & $285(74.0)$ \\
1 to 4 & $48(12.4)$ \\
$\geq 5$ & \\
\hline Husband's residence & $287(74.5)$ \\
\hline Karachi-residence & $98(25.4)$ \\
\hline Non-Karachi-residence & \\
\hline Husband's education & $127(32.9)$ \\
\hline Professional college or higher & $166(43.1)$ \\
High school & $30(7.7)$ \\
Primary school & $62(16.1)$ \\
\hline Illiterate & \\
\hline
\end{tabular}

Table 1:- this table shows the frequency of the basic education of both husband and wife, age of marriages and history of previous deliveries.

During survey we came across the induced/ spontaneous abortion was answered no that was $70.9 \%$ common as shown in figure 1. During this study we also analyzed that the residence as well as educational status of women to their husband's status. It was found that $74.5 \%$ were Karachi residences and $25.4 \%$ were non Karachi residence as shown in figure 2.

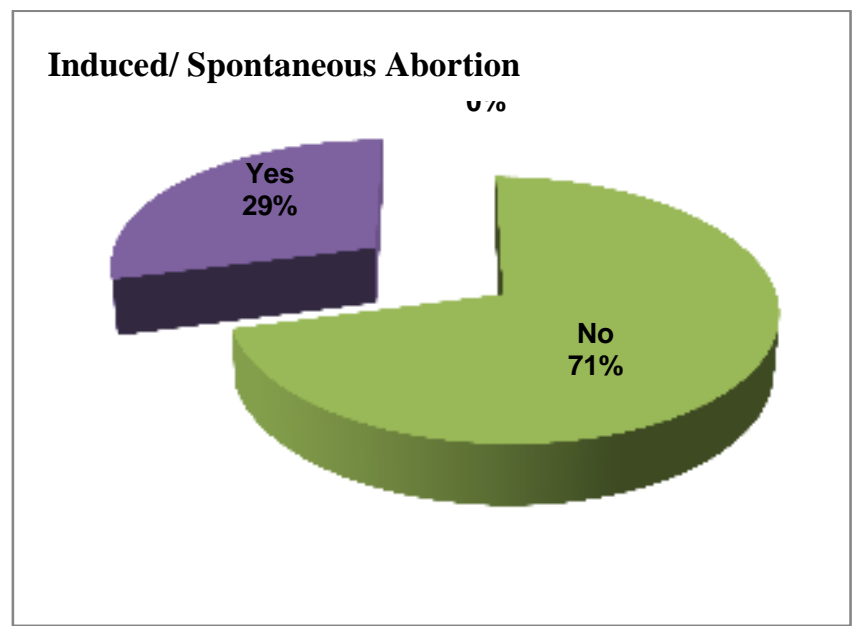

Figure 1:-This figure shows the frequency pie diagram of previously induced/ spontaneous abortion in socioeconomic variable 


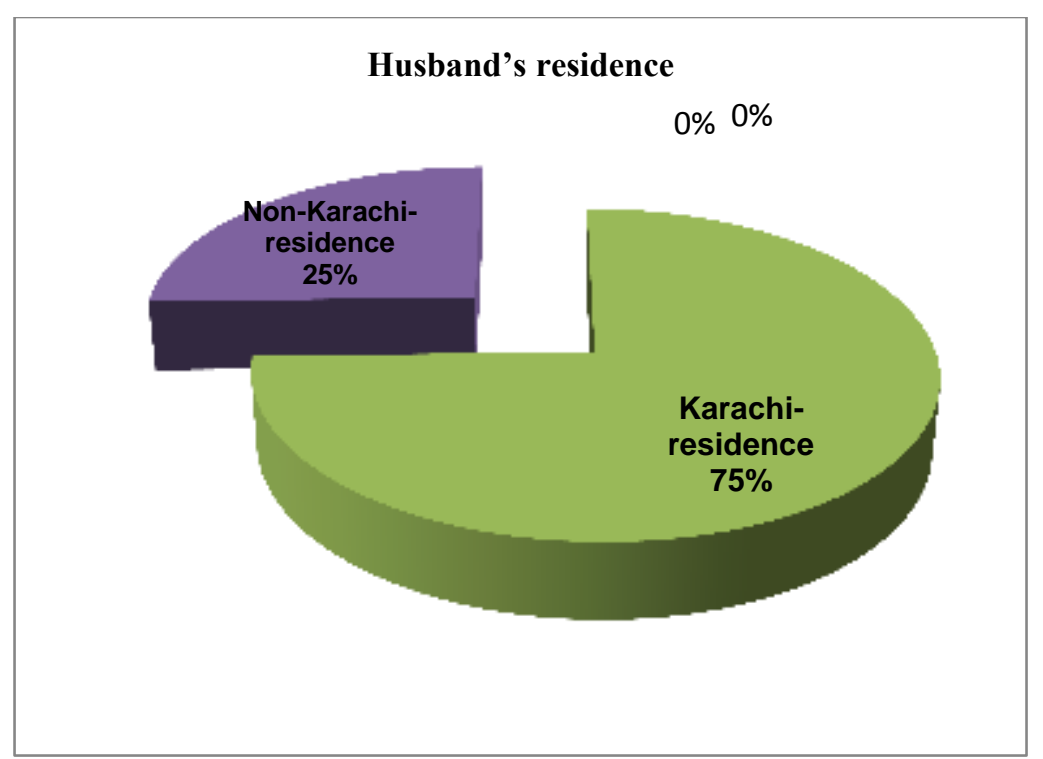

Figure 2:-This figure shows the frequency pie diagram of husband's residences in Karachi in socio-economic variable.

In the analysis of education status it was found that $43.1 \%$ received High school education, $32.9 \%$ had professional college or higher education, $7.7 \%$ went to primary school and $16 . \%$ was illiterate and it was compared with the women's educational status as shown in figure 3.

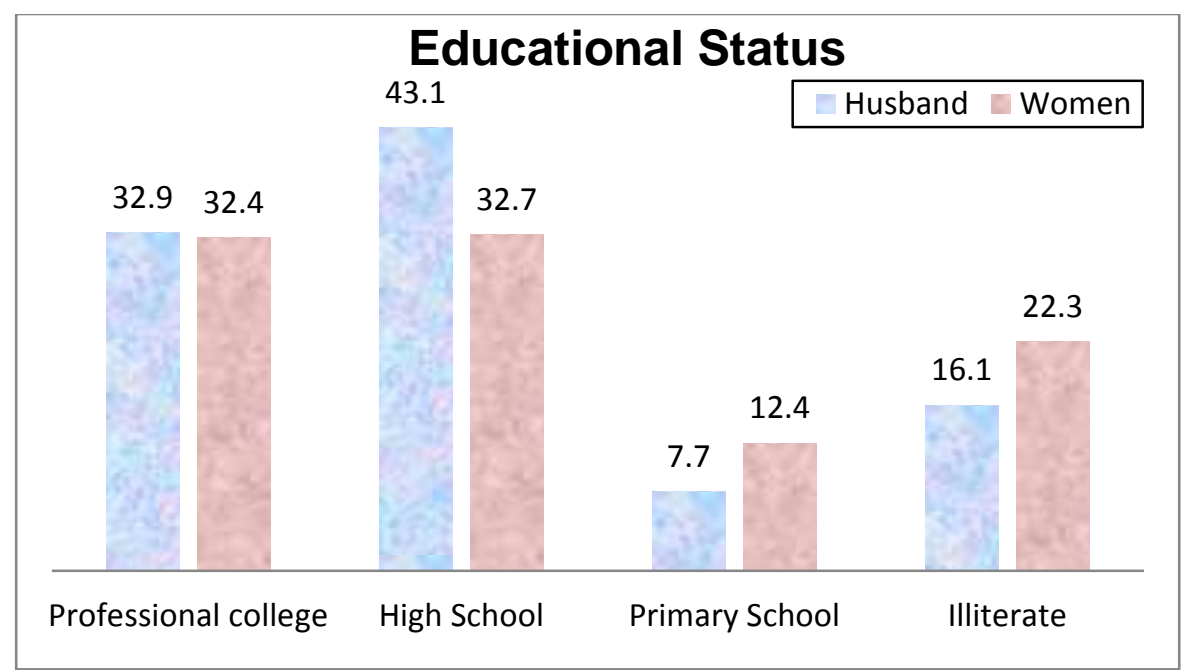

Figure 3:-This figure shows the bar chart on frequency of husband's and women educational status in socioeconomic variable.

On further analysis which was on the husbands occupational status and it was found that about $58.9 \%$ were of women whose husbands had their business or services (figure 4), and their economic status was an impact upon the utilization of maternal health care was also good. 


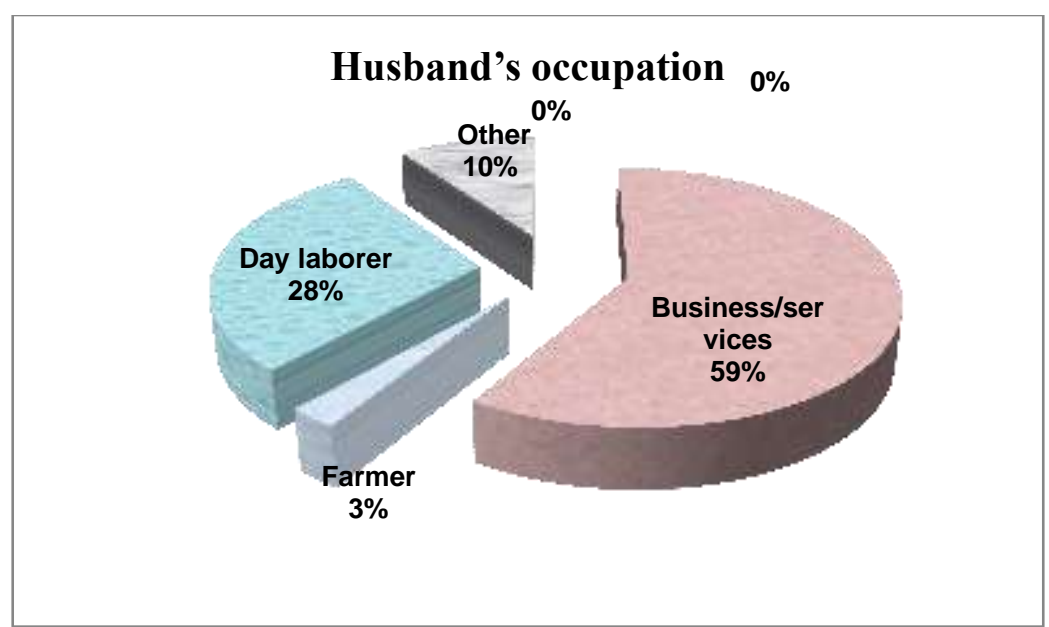

Figure 4:-This figure shows the frequency pie diagram of husband's occupation in socio-economic variable.

During our study we also came across to many questions which were related to the pregnancy and their visit to antenatal center. We analyzed that $94.2 \%$ women knew that antenatal care was important both for mother and antennal, and their outcome was that $96.8 \%$ agreed that first antenatal examination should be done within the first 3 months. On further query related with anemia, there had the knowledge about eating iron-containing food during pregnancy, $84.9 \%$ of married pregnant women answer affirmative and they also had knowledge about the importance of calcium supply, and $90.1 \%$ answer was positive as shown in table2.

\begin{tabular}{|l|l|}
\hline Variable $(\mathrm{n}=385)$ & Frequency $(\%)$. \\
\hline Do you think antenatal care is needed & \\
\hline Yes & $363(94.2)$ \\
No & $22(5.7)$ \\
\hline Should first antenatal examination be done within the first 3 months & \\
\hline Yes & $373(96.8)$ \\
No & $12(3.1)$ \\
\hline Can anemia be prevented by eating more iron-containing food during & \\
pregnancy? & $327(84.9)$ \\
\hline Yes & $58(15.0)$ \\
No & \\
\hline Does pregnant woman need calcium supply? & $347(90.1)$ \\
\hline Yes & $38(9.8)$ \\
\hline No & \\
\hline
\end{tabular}

Table 2:- this table shows the frequency of the knowledge regarding maternal health care among pregnant women.

During our study we also came across with the query asking about the antenatal visit related to the times period to maternal health care center. In our study we found that in $94.2 \%$ answered that antenatal were important need and their visits. During our analysis we found that $51.4 \%$ did not visit the antenatal care center due to the financial constrains, $23.8 \%$ answer was no need, whereas other reason for not visiting center was transportation inconvenience $(2.5 \%)$ and no time $3.1 \%$. On further analysis it was found that $34 \%$ visited once, $30 \%$ visited thrice and $21 \%$ went to the center for less than 5 time as shown in figure 5 


\section{Antenatal care (times) or Antenatal visits}

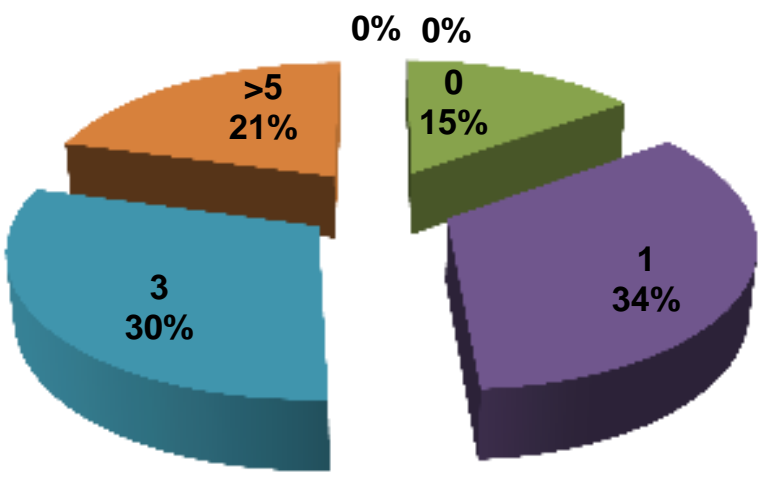

Figure 5:-This figure shows the frequency pie diagram of antenatal care and the times of visit by the pregnant women to the maternity care center in Karachi.

\section{Discussion:-}

Global reappraisals of program strategies to decrease maternal mortality clearly indicate that all pregnant women are at risk of obstetric complications. Nawzia,Y. et.al., (2009) reported that pregnancy and childbirth related complications were among the leading causes of maternal mortality. It was also reported that due to lack of knowledge about ANC and place of delivery are responsible for such a situation. An incremental maternal mortality reflects the need for addressing women's health in Pakistan. The role of the health sector in improving maternal health is to ensure availability of quality essential obstetric services to all women during pregnancy and childbirth was reported by Thaddeus $S$ et al (1994). Jafarey and Karejo (1993) suggest that economic, social and cultural factors play a more defining role in maternal deaths than medical causes.

During our study it was observed that it is a cross sectional study and was carried randomized selection in maternity homes of Liaquatabad, North Nazimabad, Gulberg and New Karachi. In Karachi, the marriage is of the women was between 15 to 45 years in different maternity homes of central district Karachi. Totally 385 were interviewed and completed the self- administered questionnaire after obtaining informed consent. This proposed study was conducted on human subject, over a period of 6 months.

Rationale of this study was assessing the knowledge regarding on maternal health care among women and awareness regarding maternal health care towards the safer pregnancy or decrease mortality and morbidity rate.

Demographics and socio-economic characteristics of the respondents were presented in table 1 provided the general background information about the interviewed respondents. Education and socioeconomic status were directly proportionate to level of awareness, regularity of antenatal visits and timing of first antenatal visit. These variables were similar to the study reported by Alam, A.Y. et al (2005). This high percentage of women from reproductive age indicates that they had better knowledge about maternity health care. It also shows their awareness about regular maternity health care which can reduce both maternal and fetal complications.Barbhuiya M.A. et.al. (2001) observed that there was association between the place of delivery and level of education and family income of the respondents. Also there were associations of utilization of antenatal care with level of education and family income of the respondents. Nisar N, et al, (2003) considered the age distribution which, $72.9 \%$ of the respondents were between 20 to 34 years and overall age range was between to 15 to 45 years., age at marriage $74.0 \%$ were above 20 years, $32.7 \%$ of them received High school education, $67.5 \%$ of the participants were house wife and $74.0 \%$ of them were between 1 to 4 previous deliveries. Previous induced/ spontaneous abortion were asked to married pregnant women $70.9 \%$ answered was no. Status of women to their husband's status we found that $74.5 \%$ of them were Karachi residences and $43.1 \%$ received High school education. 58.9\% were of women whose husbands worked in business or services. Although during analysis of data it was found that $34.0 \%$ of women visited antenatal care once time and $30.1 \%$ of women visited antenatal care three times. 
Multiple response questions were asked from all respondents to assess their knowledge of maternity health care. Approximately $94.2 \%$ women knew that antenatal care is important both for mother and pregnancy outcome and similar results are shown in a study. Nigenda $G$, et.al (2003)observed the result that about $96.8 \%$ were agreed with first antenatal examination be done within the first 3 months, anemia is prevented by eating more iron-containing food during pregnancy, $84.9 \%$ of married pregnant women answer was affirmative, Similar figures are reported in KAP study by Alam A.Y (2005) and need calcium supply, $90.1 \%$ answer was positive. $75 \%-98 \%$ subjects gave the correct answer to questions on common health knowledge, such as ' Is it needed to go to hospital when severe headache, vision problem happens, blood pressure checking, child immunization and breast feeding. Although during data analysis $63.1 \%$ were correct action after amniotic fluid breaks and newborn deformity most likely happen only $28.5 \%$ of the women got the correct answer $\& 71.4 \%$ of them were didn't know. The most common obstetric complications were pregnancy induce hypertension and hemorrhage.

Attitude of the women who actually wanted to antenatal checkup or they just came to have get instruction of breast feeding and other related information or problems related to maternal health care. 51.4\% thought the main reason for not attending antenatal care being financial constrains, $45.7 \%$ of the women wanted to get professional instruction of infant feeding from health worker, about $50.9 \%$ wished to be visited by health workers during postpartum period, breastfeeding, $73.2 \%$ of the subjects indicated to breastfeed their baby for 11 months and $85.9 \%$ of the women wanted to return to work within 2 months after delivery.

Nisar N and White F (2003) also reported that maternal mortality is undoubtedly an important public health problem in developing countries. It is possible to identify the precursors, early signs or risk factors for at least some of the major pathogenic causes of maternal deaths such as anemia, infections and rising blood pressure.

Our study results are satisfied with antenatal care, information given to them by doctors about delivery, these results are similar to the study by Langer A et al.(2002) Asked about complication experienced during last delivery, $46.2 \%$ answer was Don't know.

Awareness of when and how often they should seek care, services that should be received during prenatal visits, and signs of maternal health problems and type of feeding. Most of women favored public hospital as a place of Antenatal care visit and wished to deliver at public hospital and by the private hospital. $73.5 \%$ responded that the first antenatal care visit should occur during the less than 12 month of pregnancy, diet (how many times) during pregnancy $62.0 \%$ were taking more than before, $57.9 \%$ were favored breast feeding, while $41.0 \%$ preferred honey.

KulkarniKranti K. (2015) reported in her study that the mothers were aware of a few maternal complications of anemia during pregnancy. Most of the women's were unaware of other ill-effects of anemia like preterm labor, intrauterine fetal hypoxia, recurrent infections, failing lactation, and high output cardiac failure. This knowledge had been imparted to them largely by medical or paramedical professionals.

This could be achieved through proper antenatal screening program. Recall bias, as in this study, could be reduced by inclusion of women who are currently pregnant. This research found an association between utilization of antenatal care and awareness about the danger signals in pregnancy. This could in turn lead to decrease in maternal morbidity and mortality. Pregnant women should be encouraged to seek antenatal care as early as possible. 


\section{Reference:-}

1. Alam YA, Qureshi AA, Adil MM, Ali A. Comparative study of knowledge, attitude and practices among antenatal care utilizing and non utilizing women. JPMA 2005; 55: (2) 55-56.

2. Barbhuiya MA, Hossain S, Hakim MM, Rahman SM. Prevalence of home deliveries and antenatal care coverage in some selected villages. Bangladesh Med Res Counc Bull 2001; 27(1): 19-22

3. Jafarey SN, Korejo R. "Mothers brought dead: an enquiry into causes of delay." Soc. Sci. Med., 1993; 36: 371 72.

4. Langer A, VillarJ, Romero M, Nigenda G, Piaggio G, Kuchaisit, Rogas G, Farnot U, Pinol A, Bergsjo P, Garcia J, B erends H. Are women and providers satisfied with antenatal care. BMC Women's Health 2002; 2: 7: 68742-7.

5. KulkarniKranti K. "KAP Studies Among Indian Antenatal Women: Can We Reduce the Incidence of Anemia?" The Journal of Obstetrics and Gynecology of India; 2015 65(5):320-322

6. Nawzia Y., Khairul, A., Suman L., Mahmud, H. F., Tamjida, A. "Knowledge, Attitude and Practice regarding hospital delivery among rural married women in northern Bangladesh" Ibrahim Med. Coll. J. 2009; 3(1): 17-20.

7. Network. Feb. 1994. Access to care saves lives. Thaddeus S. Maine D. Too far to walk: maternal mortality in context. Soc. Sci. Med., 1994;38:10911110

8. Nigenda G, Langer A, Kuchaisit C, Romero M, Rojas, Al-osimy M, Villar J, Garcia J, Baqeel H, Carroli G, Farnot U, Lumbiganon P, Belizan J, Bakketeig L and Gunilla L. Women's opinions on antenatal care in developing countries: Results of a study in Cuba, Thialand, Saudi Arabia and Argentina. BMC Public Health 2003; 3: 17: 2458-3-17.

9. Nisar N, White F. "Factors affecting utilization of antenatal care among reproductive age group women (15-49 years) in an urban squatter settlement of Karachi”. J Pak Med Assoc 2003;53:47-53. 